\title{
Study on the Influence of Selected Technological Parameters of a Rotating Biological Contactor on the Degree of Liquid Aeration
}

\author{
Joanna Szulżyk-Cieplak ${ }^{1 *}$, Aneta Tarnogórska', Zygmunt Lenik' \\ 1 Faculty of Fundamentals of Technology, Lublin University of Technology, ul. Nadbystrzycka 38, 20-618 Lublin, \\ Poland \\ * Corresponding author's e-mail: j.szulzyk-cieplak@pollub.pl
}

\begin{abstract}
The subject of the research involves a rotating biological contractor with a bi-directional longitudinal flow as an element of a synchronized system of disposal and biological treatment of domestic wastewater in small-bore sewerage. The rotor design is based on a system of corrugated protective pipes, arranged in coils wound around its rotation axis. The pipes are wound in a way that enables a bi-directional flow of liquids. During the rotor rotation in wastewater, the contactor is simultaneously emptied and filled with wastewater. The role of corrugated protective pipes is twofold; on the one hand, they constitute a surface for the biofilm development and on the other, they enable the flow of liquids, thus ensuring its aeration. The contactor design aims to achieve intensive aeration of transported wastewater, which will allow for greater development of microorganism populations participating in hybrid wastewater treatment, i.e. the methods involving activated sludge and trickling filter. An analysis on the influence of rotor operation kinematics on the efficiency of liquid aeration was conducted. The aeration capacity for variable rotational speed $(0.7 \mathrm{rpm}, 1.5 \mathrm{rpm}, 2.0 \mathrm{rpm}, 3.0 \mathrm{rpm})$ and direction of the contactor rotating element were calculated. In the considered case, oxygen transfer coefficient $\mathrm{K}_{\mathrm{La}}$ was within the range of $0.011 \div 0.0231 / \mathrm{min}$. The obtained results indicate a clear connection between the system kinematics and the degree of liquid aeration in the contactor.
\end{abstract}

Keywords: biological rotating contactor, domestic wastewater, aeration, oxygen transfer coefficient

\section{INTRODUCTION}

The water and wastewater management constitutes one of the main factors influencing the living standard of residents as well as the condition and quality of the natural environment. Management of water resources should conform to the principle of sustainable development, which aims to ensure the possibility of satisfying the basic needs of both the contemporary and future generations, without upsetting the natural balance. This principle holds in the case of creating water use conditions, water protection and water resources management and it aims at achieving good ecological state of waters in a country. Proper water management must be based on a rational and modern wastewater management. As indicated in the literature data (Szulżyk-Cieplak et al. 2015, Duda et al. 2016, Błażejewski, 2012), one of the main problems of water and waste- water management in Poland is connected with the low degree of sewage disposal services characterizing the rural areas. Approximately $70 \%$ of country population uses sewerage systems, including only $37.3 \%$ or countryside residents. The basic problem of building a sewerage system in rural areas is the necessity of constructing and operating numerous small wastewater treatment plants or constructing extremely long collection and transportation systems which supply wastewater to a collective treatment plant. As relatively few residents benefit from these solutions, they are ineffective in respect to economy, ecology, and energy consumption. A solution to the issue of water and wastewater management in rural areas may involve the application of non-conventional systems. One of such systems includes simultaneous disposal and treatment of wastewater in a rotating biological contactor (Szulżyk-Cieplak et al. 2016). 


\section{STUDY AREA}

Rotating biological contactors (RBCs) are widely applied in the treatment of both the domestic and industrial wastewater. They constitute an alternative to the conventional method involving the activated sludge technology of wastewater treatment (Patwardhan 2003). Rotating contactors are characterized by the stability of treatment processes, low electric energy consumption, short retention time, low maintenance costs and ease of operation (Ghawi et al. 2009, Pathan et al. 2015). There are numerous solutions related to the construction and technology of rotating biological contactors. In her work, Ryschka (Ryschka et al. 2014) proposed four main criterions for categorization of rotating biological contactors: type of media (discs, cylinders), media submergence level (classic or submerged rotating biological contactor), type of drive (mechanical or air), and treatment method (conventional and hybrid rotating biological contactors). On the other hand, Żubrowska-Sudoł (Żubrowska-Sudoł et al. 2007) distinguished three criteria for the division of rotating biological contactors: type of wastewater flow: Moving Bed Biofilm Reactor (MBBR) and Moving Bed Sequencing Batch Biofilm Reactor (MBSBBR), share of biomass in the form of biofilm and activated sludge (conventional and hybrid MBBR), and the type of treatment process involved (removal of organic pollutants - COD, $\mathrm{BOD}_{5}$, nitrification process, denitrification process, integrated removal of $\mathrm{C}, \mathrm{N}$, and $\mathrm{P}$ compounds, anaerobic ammonia oxidation). As can be noted, in both cases there is a common classification criterion of rotating biological contactors into conventional and hybrid ones. One of the most common types of classic rotating biological contactors, in which the treatment occurs as a result of wastewater coming into contact with biofilm microorganisms, is a rotating disc biological contactor (Patwardhan 2003, Cortez et al. 2013, Hassard et al. 2015). It is made of discs centred around a horizontal shaft, submerged in wastewater to about $40 \%$ of their surface area. The surface of these discs is suitable for the development of biofilm. During their rotation, the biofilm attached to disc surface is carried into the air and aerated. Oxygen is supplied to wastewater in two ways: in the process of mixing resulting from the revolving shaft and due to the diffusion from the biofilm. As opposed to the conventional RBCs, the hybrid ones combine two factors of biological pollutant break-down in one reactor: biomass in the form of activated sludge floc and biofilm (Staehler 2004, Lenik et al. 2016).

The efficiency of biodegradation in rotating biological contactors is dependent on a number of parameters, including: the content of oxygen dissolved in wastewater, flow intensity of wastewater, content of organic compounds, rotational speed of the rotor as well as the system configuration, including the method of liquid distribution and aeration conditions (Waskar et al. 2012, Mba et al. 2007, Celenza 1999). These parameters affect, among others, maintain aerobic conditions in the reactor. It is known that the effectiveness of oxygen transfer is a critical factor determining successful application of any bioreactor for the treatment of wastewater (Chavan et al.2008). The research results (Pradeep et al. 2011, Borghi et al. 1985) indicate the concentration of dissolved oxygen in wastewater, and thus the degradation efficiency of pollutants contained within, increase along with the rotational speed of the contactor.

The biological rotating contactor with bidirectional longitudinal flow under study constitutes a novel solution (Lenik et al. 2016). The rotor, which is the main element of the device, ensures beneficial aeration conditions necessary for the biochemical pollutant degradation process and serves as a mobile trickling filter. The paper discussed the studies which enabled the evaluation of the impact of the rotor kinematic parameters on the efficiency of liquid aeration process.

\section{MATERIAL AND METHODS}

\section{Experimental set-up}

The scheme of the laboratory rig is presented in fig. 1. The test rig includes a biological contactor with a rotating element, i.e. a rotor (1), which is powered by a drive system comprising a electric geared motor (7) with a stepless adjustment of revolutions $0 \div 10 \mathrm{rpm}$. The test rig was equipped with an electromagnetic flow meter (6) which enables to control the flow rate of the influent and a RDO/DO dissolved oxygen concentration meter (3).

The rotating biological contactor with bi-directional longitudinal flow (Photo 2.1) is placed in a tank made of polyester resin (1). The central element of the RBC is a rotor (2) built of mul- 


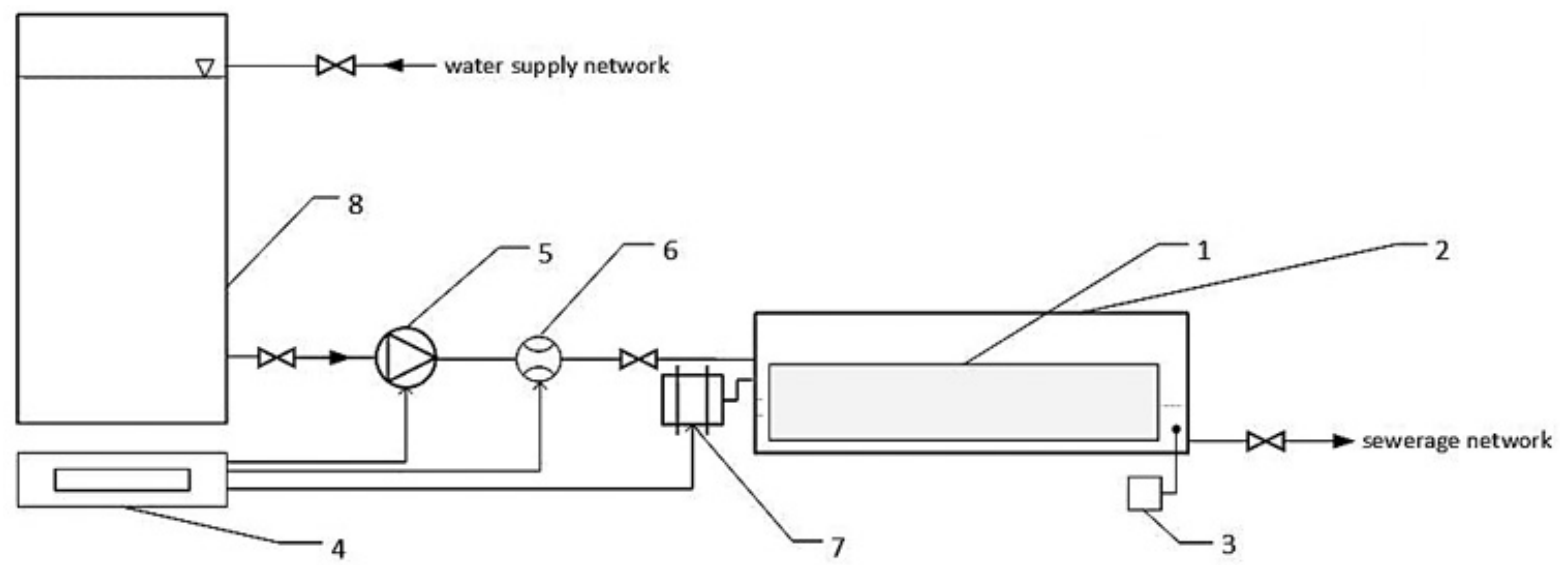

Figure 1. Schematic diagram of the laboratory rotating biological contactor: 1 - rotor, 2 - RBC housing, 3 - RDO/DO meter, 4 - control panel, 5 - peristaltic pump, 6 - electromagnetic flow meter, 7 - drive system, 8 - tank containing the test medium

tiple layers of corrugated pipes (3) wound cylindrically around its axis housing a shaft with a float (4). The amount of liquid supplied to the tank with rotor should enable its free rotation on its own axis, which enables a constant flow of the medium through the system of corrugated protective pipes. The level of medium in the tank should not exceed the height of the height of rotor drive shaft axis and - simultaneously - a half of the contactor diameter.

On the basis simulations employing the MES method, an appropriate angle of pipe winding was selected, with alternating direction and sense. This ensured the assumed flow rate and aeration of the medium (Lenik et al. 2013). The winding of corrugated pipes (Figure 2) enables a bidirectional flow of the liquid medium. The flow in layers is alternating, i.e. the fluid in the first layer flows in one direction, whereas in the next layer, the flow direction is opposite. Aeration of the liquid medium is intensified by the alternating sense and direction of corrugated channels; their number and interlacing have a significant impact on the hydrodynamics of the process involving mixing air with wastewater.

\section{Research methodology}

The degree of liquid aeration was investigated for various rotational speed of the rotor. Literature data indicate that the energy usage for motor drive increases exponentially with increasing rotational speed of the contactor, thus for the minimal operating expense the lowest rotor speeds should be selected $(0,7 \div 2,0 \mathrm{rpm})$ (Hassard et al. 2015). Therefore, the following rotational speeds were selected: $3 \mathrm{rpm}, 2 \mathrm{rpm}, 1.5 \mathrm{rpm}$ and $0,7 \mathrm{rpm}$. The rotor operation in counter-clockwise and clockwise rotation was compared as well. Each series was conducted in triplicate, whereas the

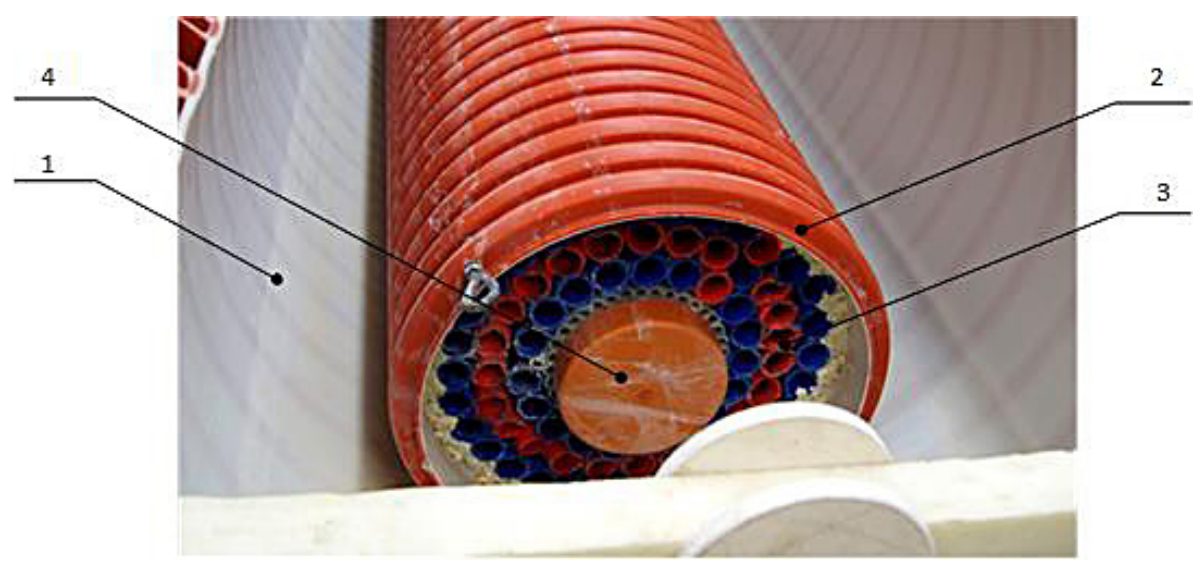

Photo 1. Laboratory model of a rotating biological contactor with bi-directional longitudinal flow: 1 - RBC housing, 2 - rotor, 3 - corrugated protective pipes, 4 - float 


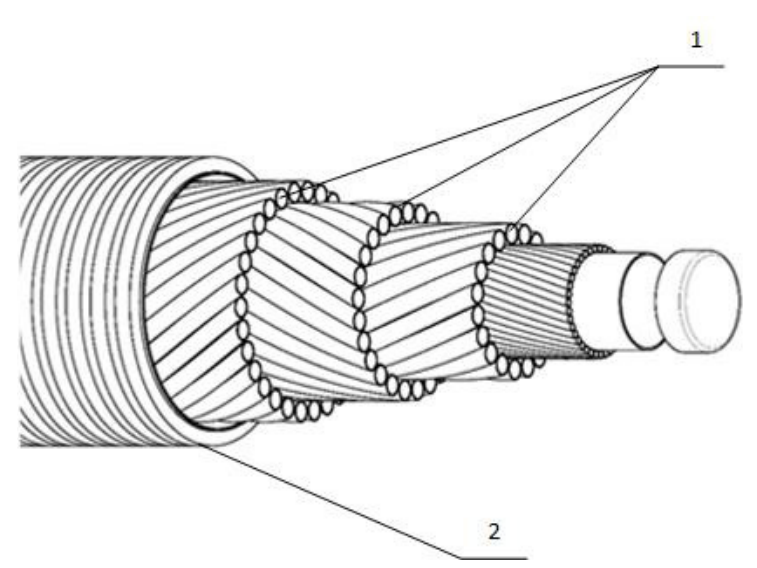

Figure 2. Arrangement of corrugated protective pipes in the rotor with bi-directional longitudinal flow:

1 - cylindrically wound layers of corrugated protective pipes, 2 - rotor housing

mean values from particular measurement series were used for the preparation of results.

The test medium comprised tap water with the temperature $\mathrm{t}_{0} \approx 16^{\circ} \mathrm{C}$. The studies were carried out with the water deoxidized by means of sodium sulfite addition $\left(\mathrm{Na}_{2} \mathrm{SO}_{3}\right)$. In order to deoxidize the required amount of tap water, the initial concentration of dissolved oxygen in sample " 0 " was measured, which was necessary to calculate the theoretical amount of the oxygen-reducing agent. The tap water was deoxidized according to the reaction (1):

$$
2 \mathrm{Na}_{2} \mathrm{SO}_{3}+\mathrm{O}_{2} \rightarrow 2 \mathrm{Na}_{2} \mathrm{SO}_{4}
$$

The required amount of the reducing agent, calculated on the basis of reaction (1), was supplemented with an extra $20 \%$. A single series of experiment required deoxidization of $90 \mathrm{dm}^{3}$ of tap water in order to achieve appropriate rotor submersion. Water was considered deoxidized, when the content of dissolved oxygen was lower than $1 \mathrm{mg} \mathrm{O}_{2} / \mathrm{dm}^{3}$.

Prior to conducting the experiment, appropriate rotational speed and rotation direction were set by means of the control panel. When suitable kinematic parameters for each measurement series were selected, an oxygen sensor was placed in the tank containing the aerated medium. The content of dissolved oxygen was read in $30 \mathrm{sec}-$ ond intervals. The liquid aeration was performed until three consecutive values of oxygen concentration with the difference lower than $1 \mathrm{mg}$ $\mathrm{O}_{2} / \mathrm{dm}^{3}$ were read.

The obtained results enabled to calculate the aeration capacity (efficiency of contactor aera- tion) for particular kinematic parameters of the system operation. The efficiency was calculated with the formula (2).

$$
K_{L} a=\frac{1}{t_{p}} * \ln \frac{C_{s}}{C_{s}-C_{t}}
$$

where: $K_{L} a-$ volumetric oxygen transfer coefficient $[1 / \mathrm{min}]$,

$t_{p}$-Total aeration time,

$\stackrel{p}{C_{s}}$ - saturation in a given temperature,

$C_{t}-$ maximum dissolved oxygen concentration

\section{RESULTS AND DISCUSSION}

The results of conducted studies were presented graphically on graphs (Fig. $3 \div 5$ ). In each of the analyzed cases, the changes in the oxygen concentration in the test medium were of certain character. An exemplary flow of the liquid aeration process was presented in Figure 3 (rotor rotational speed $\mathrm{v}=3 \mathrm{rpm}$, counter-clockwise and clockwise rotation).

While analyzing the graph, one can observe a slightly faster increase pertaining to the concentration of dissolved oxygen in the test medium when clockwise rotation was applied. A similar trend was observed for the remaining rotation speeds, i.e. $\mathrm{v}=2 \mathrm{rpm}, \mathrm{v}=1.5 \mathrm{rpm}$ and $\mathrm{v}=0.7 \mathrm{rpm}$.

The influence of rotor rotational speed on the aeration degree of the test medium was analyzed. Fig. 4 presents the results of the studies conducted for variable rotational speed $(\mathrm{v}=1.5 \mathrm{rpm}, 2 \mathrm{rpm}$, $3 \mathrm{rpm}$ ) and clockwise rotation.

The data presented on the graph (Fig. 4) indicate the dependency of the liquid aeration degree on the rotor rotational speed. Increasing the rotor rotational speed simultaneously raises the efficiency of RBC operation in terms of the liquid aeration degree. The results obtained coincide with the results of other researchers on the subject of rotating disc contactors. Moreover, the conducted research shows that the increase in rotational speed reduces the time required for a liquid to stabilize, i.e. mixing of a reducing agent with the medium in order to carry out the aeration process properly. A similar dependency was observed in the case of counter-clockwise rotation. Taking into account operating expense of the process, the results obtained indicate that the optimal solution appears to be the rotor speed of $\mathrm{v}=2 \mathrm{rpm}$ and the aeration time of $t=60 \mathrm{~min}$. 


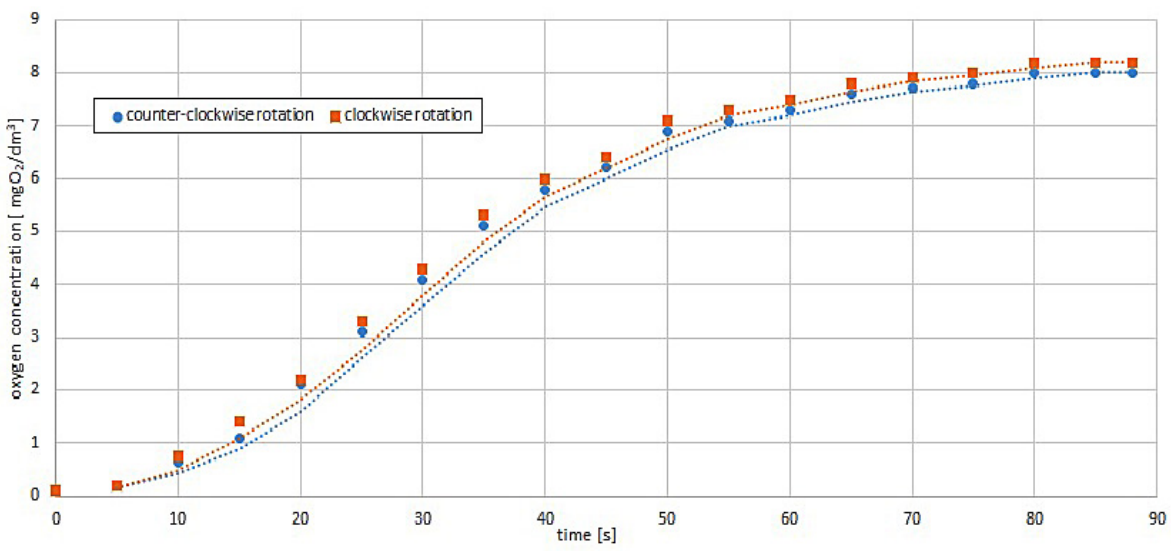

Figure 3. Changes in the concentration of dissolved oxygen in the test medium for the rotational speed of $3 \mathrm{rpm}$.

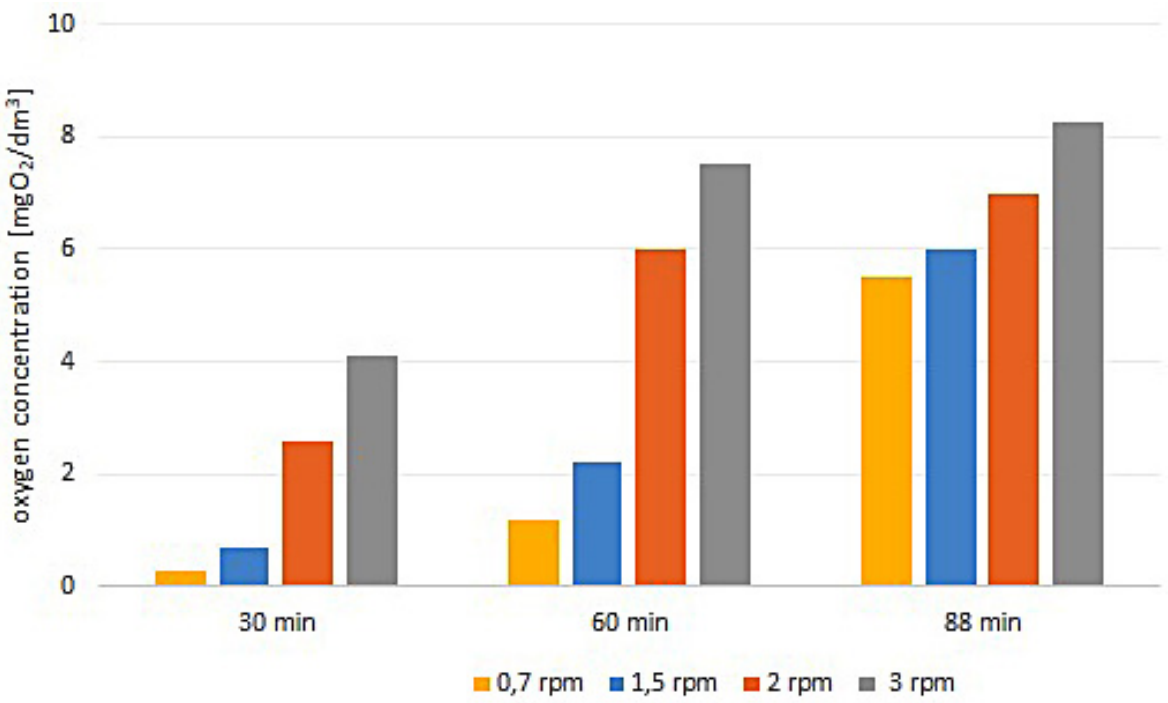

Figure 4. Oxygen concentration in the test medium following the aeration time $t=30 \mathrm{~min}, 60 \mathrm{~min}$ and $88 \mathrm{~min}$ for variable rotor rotational speed $(\mathrm{v}=0.7 \mathrm{rpm}, 1.5 \mathrm{rpm}, 2 \mathrm{rpm}, 3 \mathrm{rpm} \mathrm{min})$ with clockwise rotation applied

The studies conducted enabled to determine the volumetric oxygen transfer coefficient $\left(\mathrm{K}_{\mathrm{La}}\right)$ for variable kinematic parameters of the system. The calculations were performed on the basis of the dependency (2), whereas the calculations results were presented in Table 1 and a graph (Fig. 5).

The obtained results indicate an exponential dependency of the liquid aeration efficiency on the kinematic parameters characterizing the system, i.e. direction and rotational speed of rotor. The highest volumetric oxygen transfer coefficient was obtained for the rotational speed of $\mathrm{v}=3 \mathrm{rpm}$, clockwise. Overall, comparing the results obtained with the results obtained by other researchers (Boumansour et al. 1998, Paolini 1986), it can be concluded that the applied constructional solution of the reactor in relation to the degree of liquid aeration gives satisfactory results. For rotational speed of $\mathrm{v}=0,7 \div 3.0 \mathrm{rpm}$, higher value of oxygen transfer coefficient was obtained as compared to the value obtained by Boumansour and Paolini. (Fig. 5).

\section{CONCLUSIONS}

1. Ensuring adequate aerobic conditions constitutes one of the main factors influencing the efficiency of reactor operation based on biochemical processes carried out under aerobic conditions. The obtained results indicate a possibility adjusting the aeration degree of liquids in a reactor - which is one of the decisive parameters connected with the efficiency and quality or rotating biological contactor operation - through rotor operation kinematics. 
Table 1. Values of volumetric oxygen transfer coefficient for variable kinematic parameters in the system.

\begin{tabular}{|c|c|c|c|c|c|}
\hline $\begin{array}{c}\text { Rotor } \\
\text { rotational } \\
\text { speed } \\
\text { [rpm] }\end{array}$ & $\begin{array}{l}\text { Liquid aeration time } \\
\qquad \text { [min] }\end{array}$ & $\begin{array}{l}\text { Temperature of the } \\
\text { test medium }\left[{ }^{\circ} \mathrm{C}\right]\end{array}$ & $\begin{array}{c}\text { Saturation in a } \\
\text { given temperature } \\
{\left[\mathrm{mg} / \mathrm{dm}^{3}\right]}\end{array}$ & $\begin{array}{c}\text { Concentration of } \\
\text { dissolved oxygen. } \\
{\left[\mathrm{mg} / \mathrm{dm}^{3}\right]}\end{array}$ & $\begin{array}{c}\text { Volumetric oxygen } \\
\text { transfer coefficient } \\
{[1 / \mathrm{min}]}\end{array}$ \\
\hline \multicolumn{6}{|c|}{ Counter-clockwise rotation } \\
\hline 3 & 90.5 & 17.2 & 9.75 & 8.16 & 0.020 \\
\hline 2 & 94.5 & 18.2 & 9.54 & 7.02 & 0.014 \\
\hline 1.5 & 97.0 & 17.6 & 9.54 & 6.26 & 0.011 \\
\hline 0.7 & 99.0 & 17.5 & 9.54 & 5.52 & 0.008 \\
\hline \multicolumn{6}{|c|}{ Clockwise rotation } \\
\hline 3 & 88.5 & 17.8 & 9.54 & 8.26 & 0.023 \\
\hline 2 & 92.5 & 18.0 & 9.54 & 7.10 & 0.015 \\
\hline 1.5 & 95.0 & 17.2 & 9.75 & 6.30 & 0.012 \\
\hline 0.7 & 98.0 & 17.5 & 9.54 & 5.60 & 0.009 \\
\hline
\end{tabular}

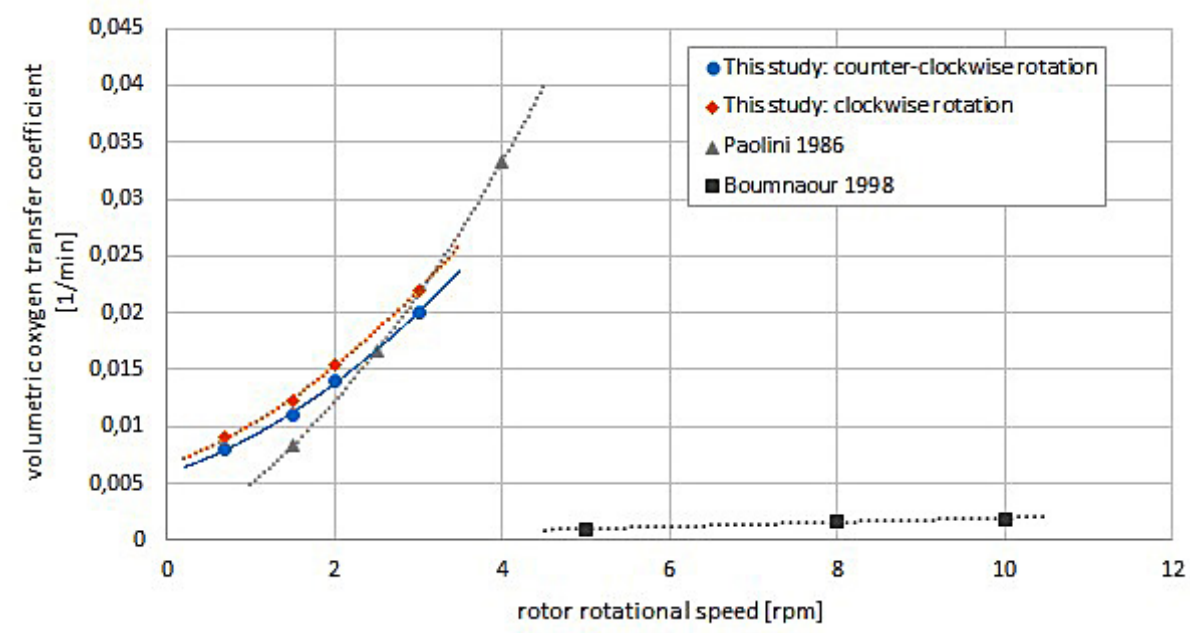

Figure 5. Dependence of volumetric oxygen transfer coefficient $\mathrm{K}_{\mathrm{La}}$ on the rotor rotational speed

2. The volumetric oxygen transfer coefficient $\mathrm{K}_{\mathrm{La}}$ was determined on the basis of the measurements pertaining to the dissolved oxygen, which were carried out until saturation was achieved. In the case considered, $\mathrm{K}_{\mathrm{La}}$ was within the range of $0.011 \div 0.0231 / \mathrm{min}$, which is a satisfactory result as compared to the results of other researchers. Taking into account operating expense of the process, the results obtained indicate that the optimal solution appearss to be the rotor speed of $\mathrm{v}=2 \mathrm{rpm}$ and the aeration time of $\mathrm{t}=60 \mathrm{~min}$.

3. A comprehensive examination of various alternatives for the system kinematics allowed for selection of the suitable RBC configuration to be employed in a demonstrative sewerage network. This device ensures adequate aeration conditions, necessary for the biochemical pol- lutant breakdown process and simultaneously serves as a Moving Bed Biofilm Reactor. The solution employed does not require construction of the mechanical parts found in the conventional treatment plants and wastewater can be supplied directly to the tank with a rotor, immediately followed by the aeration. Therefore, the application of the rotor as an element of a simultaneous wastewater discharge and treatment system in small settlement units, may reduce the investment costs of the water and wastewater management.

\section{REFERENCES}

1. Błażejewski R., 2012. Status and opportunities for water and sewage infrastructure in Poland (In Polish), Gaz, Wodna i Technika Sanitarna, 2, 49-51. 
2. Borghi M., Pallazi E., Parisi F., Ferraiolo G., 1985. Influence of process variables on the modelling and design of a rotating biological surface, Water Research, 19(5), 573-580.

3. Boumansour B.E., Vasel J.L., 1998. A new tracer gas method to measure oxygen transfer and enhancement factor on RBC, Water Research, 32(4), 1049-1058.

4. Celenza G., 1999. Industrial Waste Treatment Process Engineering: Biological Processes, Vol. II. CRC Press Taylor \& Francis Group.

5. Chavan A., Mukherji S., 2008. Dimensional analysis for modeling oxygen transfer in rotating biological contactor, Bioresource Technology, 99(9), 3721-3728.

6. Cortez S.,Teixeira P., Oliveira R., Mota M., 2013. Bioreactors: Rotating Biological Contactors, Encyclopedia of Industrial Biotechnology, Press John Wiley \& Sons, 1013-1030.

7. Duda A., Szulżyk-Cieplak J, Lenik, K., 2016. Innovative system of simultaneous transportation and treatment of sanitary wastewater in scattered dwelling areas, Journal of Ecological Engineering, 17(5), p. 84-89.

8. Ghawi A.H., Kris J., 2009. Use of rotating biological contactor for appropriate technology wastewater treatment, Slovak Journal of Civil Engineering, $3,1-8$.

9. Hassard F., Biddle J., Cartmell E., Jefferson B., Tyrrel S., Stephenson T., 2015. Rotating biological contactors for wastewater treatment - A review, Process Safety and Environmental Protection, 94, 285-306.

10. Lenik K., Korga S., Kozera R., Szalapko J., 2013. FEM and Flow Simulation Module for selecting parameters in rotors flow systems, Archives of Materials Science and Engineering, 2(59), 69-75.

11. Lenik K., Skubisz W., 2016. Urządzenie i sposób do biologicznego oczyszczania ścieków, Zgłoszenie nr (21) 411985, Biuletyn Urzędu Patentowego, 44(22), 19-19.

12. Mba D., Bannister R., 2007. Ensuring effluent stan- dards by improving the design of Rotating Biological Contactors, Desalination, 208, 204-2015.

13. Paolini A.E., 1986. Effect of Biomass on Oxygen Transfer in RBC Systems, Water Pollution Control Federation, 58(4), 306-311.

14. Pathan A.A., Rasool B.M., Memon F.A., 2015. Effect of flow rate and disc area increment on the efficiency of rotating biological contactor for treating greywater, Mehran University Research Journal of Engineering \& Technology, 2(34), 99-106.

15. Patwardhan, A.W., 2003. Rotating biological contactors: a review, Industrial \& Engineering Chemistry Research, 42, 2035-2051.

16. Pradeep N.V., Hampannavar U.S., 2011. Biodegradation of phenol using rotating biological contactor, International Journal of Environmental Sciences, 2(1), 105-113.

17. Ryschka, J., Rak, A., 2014. Analysis the efficiency of biological wastewater treatment in air-driven rotating biological contactor (In Polish), Gaz, Woda i Technika Sanitarna, 8, 303-306.

18. Staehler, T. 2004. Aerobous continual method of biologically treating sewage (in Polish), Zgłoszenie patentowe PL 186625. 27.02.2004.

19. Szulżyk-Cieplak,J., Lenik, K., Ozonek, J., 2015. Assessment of rural sewerage system on the example of Lublin province (In Polish), In: Chmielewski J., Szpringer M. (Ed.), Zdrowie, praca, środowisko - współczesne dylematy, Warszawa, Instytut Ochrony Środowiska - PIB, 241-252.

20. Szulżyk-Cieplak J., Duda A., Lenik K., 2016. The selection of design parameters of the rotating biological contactor using tracer studies, Rocznik Ochrona Środowiska, 2(18), 897-908.

21. Waskar V.G., Kulkarni G.S., Kore V.S., 2012, Review on process, application and performance of rotating biological contactor (RBC). International Journal of Science and Research Publications, 2(7), 1-6.

22. Żubrowska-Sudoł, M., Jasińska, A., 2007, Division of reactors with mobile beds (In Polish), Gaz, Woda i Technika Sanitarna, 3, 29-31. 